\title{
7. Is Implementation Only About Policy Execution?: Advice for public sector leaders from the literature
}

\author{
Evert Lindquist and John Wanna
}

\section{Introduction}

We were asked to undertake a review of the literature on policy implementation, delivering policy reform, and organisation change and to explore the implications for public sector leaders charged with implementing public policy in fluid, often turbulent, environments. The goal was to inform a short, accessible guide for public sector leaders (State Services Authority 2011). The research questions animating that review (with some adaptation) were as follows:

- How is the operating environment of the public sector distinctive with respect to the challenges of implementation?

- How should public sector leaders anticipate the need for policy reform and understand implications for their agencies, which may or may not have been involved in the design and implementation of the reforms?

- How do public sector agency leaders work with governments and other public organisations to anchor reform? What leadership strategies and organisational capabilities are needed?

- What are key success factors associated with successful implementation and how do public sector agency leaders know when reform has stuck? What are the indicators and metrics for assessing performance for implementation?

- Why do reforms and implementation become derailed or lose momentum?

The volume and breadth of the policy implementation, policy reform and organisational change literature make it impossible, given our space constraints, to systematically review all of the contributions and provide detailed account of debates and insights. The purpose of this chapter is to provide a more detailed and accessible account of the literature on policy implementation, delivering policy reform, and organisation change, as well as to develop an integrating framework. It also seeks to identify concepts and theoretical frameworks approaches that will be useful to public sector executives seeking to anticipate, implement and anchor government commitments in ever-changing environments, including shifting and emerging new government priorities, and to mobilise their organisations to maintain focus and be agile. 
There are several themes we would like to foreshadow. First, strategies and advice on anchoring policy implementation should directly acknowledge the conditions of generalised overload of the governance systems, the shifting attention spans of governments, the rapidly evolving environment of public agencies, the multiple demands on agencies, and the inherent complexity of most policy problems. All of these factors point to the need for anticipatory, focused and strategic agency leadership. Second, effective implementation for any agency - regardless of the nature of the reform initiative or how central the agency was in its design and implementation - requires clarity of mandate and reasonable expectations, sufficient capability for carrying out responsibilities, and recognition that implementation is an administrative and political challenge requiring ongoing engagement with ministers, stakeholders, and other public agencies, often associated with other levels of government. Third, a huge tension inherent in delivering policy reform is the need for public sector leaders to strike the right balance between implementing (or imposing) a given strategic reform versus leaving scope for learning and adjustment in the face of unknown and/or changing conditions for implementing organisations.

\section{The literature on policy implementation: An overview}

The literature on policy implementation, which emerged during the 1970s and gained a great deal of recognition because of Pressman and Wildavsky's seminal Implementation: How great expectations in washington are dashed in Oakland, or why it's amazing that federal programs work at all (1973). However, Pressman and Wildavsky's contribution, though a landmark, was part of burgeoning scholarly interest across several countries about why policy plans failed to meet their stated objectives. Moreover, this work was only one stream of writing on policy development, policy and program evaluation, knowledge and research utilisation, policy termination, etc. It was part of the policy movement that included establishing policy schools at universities and policy analysis and research units in government. The policy implementation literature was seen as exploring one phase of the larger policy cycle, which has always considered the implications of one phase for others and transcended artificial boundaries (for example, Hogwood and Gunn 1984; Bridgman and Davis 2000; Pal 1997).

The literature on policy implementation is vast; there have been a succession of books (for example, Pressman and Wildavsky 1973; Bardach 1977; Van Horn 1979; Nakamura and Smallwood 1980; Williams 1980; Williams et al. 1982; Mazmanian and Sabatier 1983; Goggin et al. 1990; Hill and Hupe 2009), collections and special issues (for example, Mazmanian and Sabatier 1981; Williams 1982; Ingram and Mann 1980; Palumbo and Calista 1990; Schofield and 
Sausman 2004; Honig 2006a), and hundreds of articles and chapters following the explosion of literature during the 1970s and 1980s. Moreover, many of the ideas reflect and build on broader insights permeating the policy-making and public management literature. An extensive set of references is provided at the end of this chapter (for more, see Hill and Hupe 2009; Goggin et al. 1990).

To begin with, however, a few preliminary observations are in order. First, since the early 1970s contributors have grappled with how to deal with 'wicked problems' even though that nomenclature only recently came into common use (the term emerged with Rittel and Webber 1973). Second, the implementation literature has always had a practical orientation (that is, providing advice to political and administrative leaders alike), even though it can be theoretically and empirically informed in sophisticated ways - that said, its focus has been on chronicling how implementation worked and whether policy and program goals were achieved and, if not, explaining why not. Much of the literature is more evaluative than managerially inclined. Overviews of the trajectory of the literature can be found in numerous sources (Hill and Hupe 2009; Winter 2003; May 2003; O'Toole 2003; Meyers and Vorsanger 2003) and in almost every article.

Finally, over the decades there has been considerable navel-gazing about the state of the literature on policy implementation (for example, Hjern 1982; Hill 1997; Lester et al. 1987; Lester and Goggin 1998; Winter 1999; deLeon 1999a, 1999b; Schneider 1999; Lester 2000; Kettunen 2000; Meier 1999; Potoski 2001; Goggin et al. 1990; O'Toole 1986, 2000, 2004; Barrett 2004; Scofield 2001, 2004; etc.). One claim surfacing in the late 1990s was that the literature had lost momentum, but Saetren (2005) and this chapter shows quite the opposite; there is more writing on aspects of implementation in a greater variety of journals, with diverse themes taken up in different ways, under different labels, and often in distinct substantive fields (for example, education, health, etc.).

\section{The early trajectory of the policy implementation literature}

The earliest contributions to the literature opened up the field by pointing to the gap between policy goals and results (for example, Pressman and Wildavsky 1973). In particular, there was considerable interest in how policies and programs legislated at the national or federal level of government might not have achieved the hoped-for results on the ground, and how they could take shape in very different ways in different sub-national and local jurisdictions. Interestingly, even though the terminology of 'wicked problems' and 'service-delivery networks' were not invoked at the time, a review of the literature quickly shows that most of the writing of the 1970s and 1980s were indeed about national government 
programs seeking to address tough social and other challenges, and often sought to do so in collaboration with state-level governments and non-profit and other providers. By the late 1990s and early 2000s, of course, scholars and practitioners alike developed an interest in the notion of policy and service-delivery networks, and this language permeates modern implementation studies and discourse.

All accounts found in the implementation literature acknowledge that early contributions rapidly divided into two broad streams and orientations:

- Top-down perspectives and analysis seeking to explain why policy did not have its intended effects in terms of outcomes or exploring better ways to implement policy as designed. Hill and Hupe (2009) suggest that the exemplars of the top-down approaches include Pressman and Wildavsky (1973), Van Meter and Van Horn (1975), Bardach (1977), Mazmanian and Sabatier (1981), and Hogwood and Gunn (1984). In this stream of literature, policy outcomes that differed from those intended were seen as failures, distortions, evidence of lack of willingness of staff in field operations, legislative interference, other levels of governments, and third-party providers to comply with central policy edicts. In addition to seeking to identify the causes of divergence from intended policy, such writing was dedicated to finding better ways for central authorities to anticipate implementation challenges and the behaviours of delivering agents, to better coordinate implementation activities within and across governments, and to identify better tools and instruments for achieving policy goals and objectives. This writing, usually examining US programs (but not always), often explored implementation issues for the national government in the context of federalism, working with state and local governments and non-profit and for-profit organisations to deliver programs.

- Bottom-up perspectives on implementation seeking to explain why outcomes diverged from policy intentions by studying the behaviour of actors in the implementation chain: field staff and in other government and delivery organisations (either dysfunction or better-than-designed approaches). Seminal studies explored the reactions of implicated organisations and staff (Van Meter and Van Horn 1975), the reactions of overloaded street-level bureaucrats (Weatherly and Lipsky 1977; Lipsky 1980), the behaviour of individuals, groups, and organisations reacting in organisational and political ways to central plans (Hjern 1982; Ingram 1977), the under-specification and often poorly communicated policies and subsequent interpretation by staff and others (Yanow 1993), and the natural effects of ambiguity, diverging interests, bargaining and negotiation (Matland 1995; Barrett 2004).

These emphases and divisions in the literature persist to this day, notwithstanding efforts to integrate the two perspectives. Many practitioners and scholars continue to seek to find better ways to execute or measure the impact of policy as originally defined 
in legislation, while others are more interested in the dynamics of implementation, exploring issues from the vantage point of implementation agents such as regional field offices, frontline staff, non-government delivery organisations, and clients.

Interestingly, at an early point these analytic streams were heavily informed by organisation theory (for example, Van Meter and Van Horn 1975; Elmore 1979; Berman 1978; Barrett and Fudge 1981; Montjoy and O'Toole 1979; O'Toole and Montjoy 1984) and this continues to this day (for example, Honig 2006a, 2006b). This takes the load off this chapter to review the literature on organisational theory, behaviour, change, and development, because many insights have long been factored into implementation analysis, albeit in varying ways. Their insights remain salient for policy practitioners and agency heads to this day.

\section{Integrative implementation frameworks: Top-down/bottom-up}

While the top-down and bottom-up perspectives remain distinct traditions and themes in the policy implementation literature, there were early efforts to develop comprehensive and integrative theories and frameworks. These contributions recognised that the top-down and bottom-up perspectives each identified important variables and issues. Some of these contributions include the following:

- Backwards-mapping: Elmore's (1979) seminal contribution focused on why and how policy designers should engage in backwards-mapping when undertaking top-down design to anticipate frontline dynamics and behaviours. He suggests that it is important to maximise discretion for managers closer to where policy is delivered. This perspective goes beyond the 'chain-of-steps' approach of Pressman and Wildavsky (1973) or the guerrilla tactics implied by Bardach's Implementation Game (1977). Elmore sees policy as partially emergent, and implementation likely requiring bargaining and negotiation, and asks whether policies as conceived anticipate the behaviour of frontline staff.

- Contingency and implementation: Berman (1978, 1980) suggests that policy implementation strategies differ depending on the scope of change, degree of technical certainty, degree of consensus, amount of coordination required, and the stability of environment. For the purposes of analysis, he set out two very different implementation strategies - programmed versus adaptive - with the former better specified and more about compliance in tightly coupled systems, and the latter less defined, more emergent in loosely coupled systems, and shaped relatively more further into the process and from the bottom-up. Neither is innately superior; their efficacy depends on the circumstances. 
- Ambiguity and conflict: Like Berman (1978), Matland (1995) sought to reconcile top-down and bottom-up perspectives with a contingency approach by suggesting that different implementation styles are effective for different contexts. His much-cited typology identified four distinct styles and contexts: administrative, for low ambiguity and conflict environments; political, for high conflict and low ambiguity situations; experimental, for low conflict and high ambiguity contexts; and symbolic implementation when ambiguity and conflict are high.

- Embracing complexity: Mazmanian and Sabatier (1983) drew on Sabatier (1986) to develop a sophisticated integrative framework, embracing all of the top-down and bottom-up factors identified in the literature. It included all as variables that might influence and condition the implementation process (see Diagrams 1 (p. 215) and 2 (p. 216)). They note that implementation can be evaluated from many different vantage points: the centre, periphery and target groups (Mazmanian and Sabatier 1983, p. 11). However, their work ultimately used enacted legislation as a point of departure and sought to explain why policies do not succeed and the circumstances under which they can be better specified to achieve desired goals.

- Interdependence and task requirements: O'Toole and Montjoy (1984) drew on organisation theory to analyse different potential patterns in 'interorganisational policy implementation'. Informed by the seminal work of Thompson (1967), this approach elegantly considers the different kinds of interdependence among organisations flowing from the nature of the policy, the distribution of authorities, and task requirements. It is congruent with bottom-up approaches focusing on implementing entities, and the need to collaborate across agencies (Bardach 1997) and with frontline officials and service delivery entities.

- Exchange and bargaining: Stoker (1989) offers an 'implementation regime' framework designed to embrace top-down features and concerns (central authority seeking compliance, despite the challenge of complexity and securing intended objectives in federal systems) with bottom-up (competing values, diffuse authority, and likely bargaining and conflict resolution among the middle and frontline organisations, and clients). Policy implementation is cast as an exchange process where value can be added by different actors, and does not presume that all politics is completed in design phase. Moreover, the process deals with unanticipated or insufficiently acknowledged matters, and sees implementation as a bargaining game and local participants as problemsolvers. The framework anticipates a dynamic and evolutionary approach from initiation to routinisation to reformulation. Ultimately, Stoker sought to show how broader governance regimes as rules and norms condition these dynamics and produce accommodation, and broaden our notions of how cooperating can be secured and what constitutes 'performance'. 
- Information and incentives: Goggin et al. (1990) set out a dynamic model of implementation which they call a 'communications' model of intergovernmental policy implementation. This taps not only into cybernetic models, but also multi-level institutions, and includes variables pertaining to inducements, constraints, resources, federal and state ecological capacity, feedback from actors to policy authorities, and outcomes. Ultimately, though, this approach is about ascertaining the effectiveness of different policies across sectors and jurisdictions, and is less about developing a better strategic or managerial approach. The framework is intended to inform more systematic social science research on implementation, whereas Mazmanian and Sabatier (1983) sought to speak to scholarly and practitioner audiences.

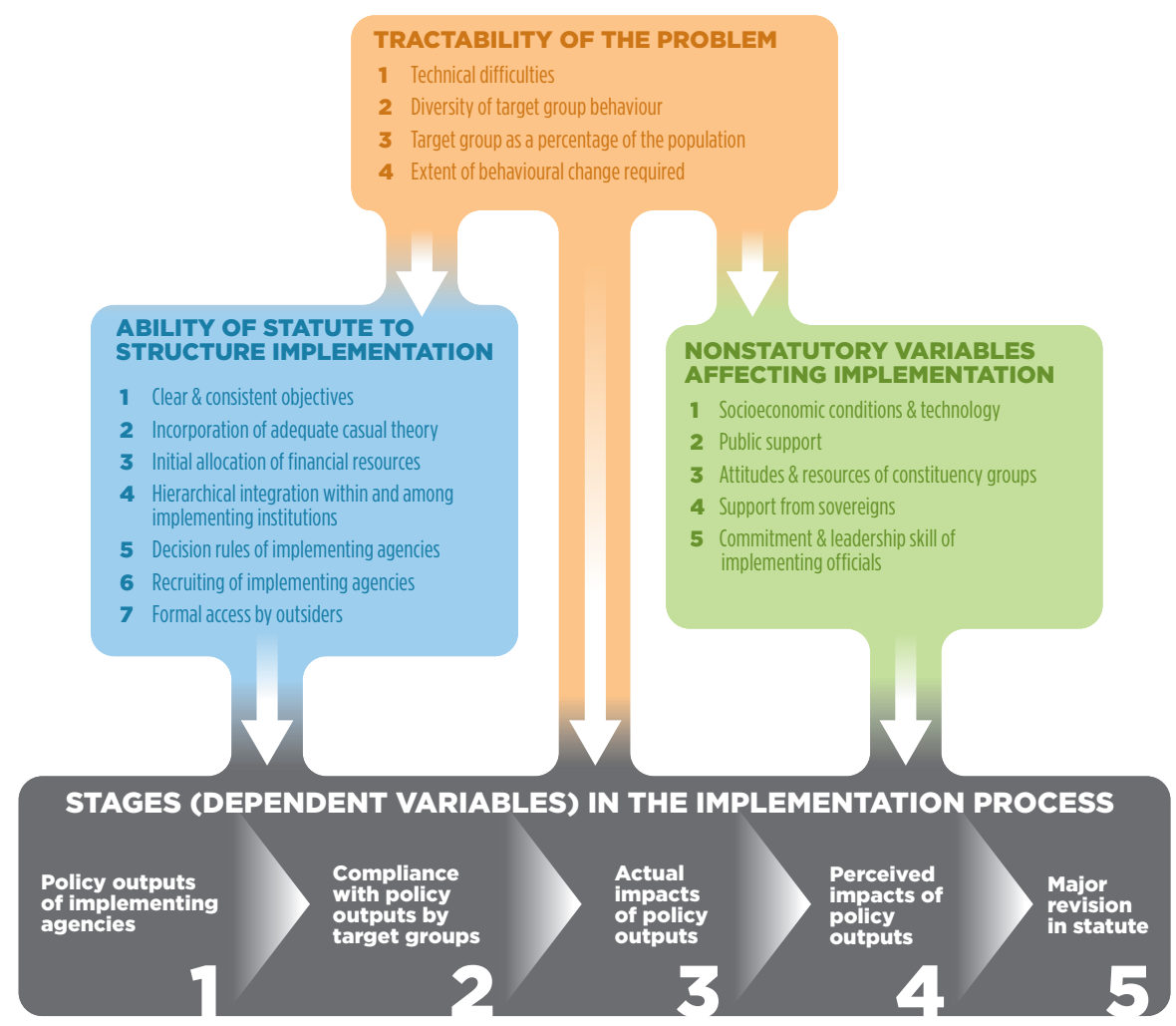

\section{Diagram 1: Variables involved in the implementation process}

Source: Adapted from Mazmanian and Sabatier 1983. 


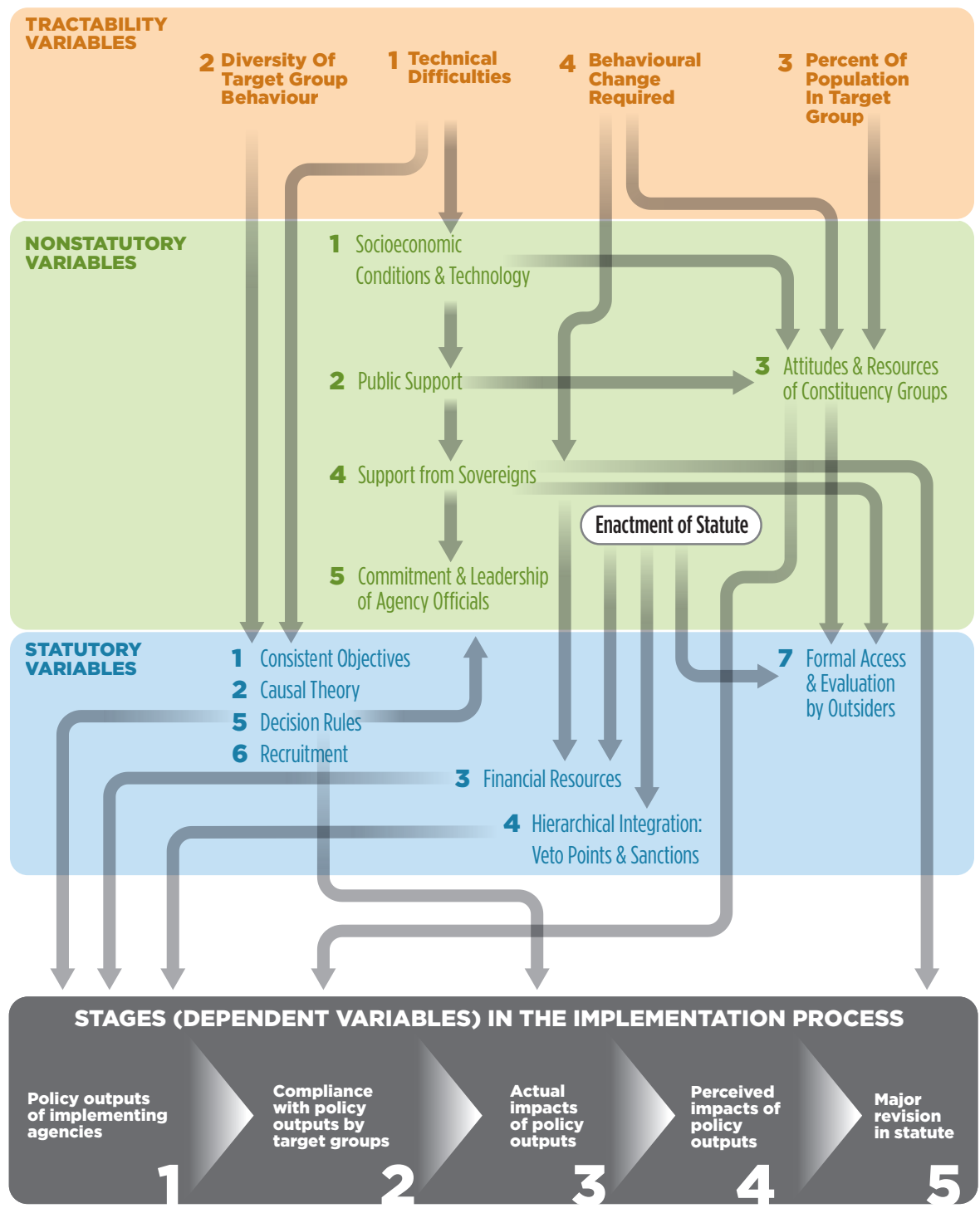

\section{Diagram 2: Variables and stages affecting the implementation of a statute}

Source: Adapted from Mazmanian and Sabatier 1983.

These efforts to integrate and acknowledge that designing effective policy and implementation strategies requires understanding the nature of a policy, its broader political history and environment, its complexity, and the organisational and broader environment. There is no one best way to implement. Successful implementation strategies are contingent, and will differ across policies, domains, and jurisdictions. As Berman (1978), Mazmanian and Sabatier (1981), and Matland (1995) suggest, these strategies and observed behaviours might 
vary with respect to the level of analysis and over time. Importantly, an implication of Stoker (1989) is that a policy may be underspecified, whether by design or not, for the implementation challenges at hand.

Another form of integration, similar to Goggin et al. (1990), can be found in a wide range of systematic efforts under the labels of 'evaluations', 'trials and pilots' and 'quasi-experiments' which, in different ways, seek to measure and account for variation in the performance and efficacy of policies. These empirical and data-rich (big-N) studies also started to emerge and gather steam as part of the evaluation stream in the policy analysis movement in the 1960s and 1970s. We do not have the space here to review such studies, but a review of Lynn et al. (2001), Ingraham and Lynn (2004), and the Journal of Policy Analysis and Management over the last 10 years will quickly provide a sense of this perspective. In order to account for differing performance, investigators specify indicators similar to many of the factors and variables considered important to implementation researchers, including resources, actors, constraints, incentives, time, etc. However, the ultimate focus differs; the emphasis in these studies is on accounting for and explaining performance, whereas implementation studies have typically sought to understand strategies and capacities. Indeed, often pilots and trials were put in place to avoid full 'testing' by rolling out a largescale, national policy intervention.

\section{Recent developments in the policy implementation literature}

The implementation literature has continued to grow and branch out during the 1990s and early 2000s (Saetren 2005). The best single source for an overview of the scholarly literature is the second edition of Hill's and Hupe's (2009) comprehensive monograph, which is targeted for researchers rather than practitioners. Here we will briefly describe the ways in which the literature has deepened, some of which has involved levering insights from related streams of literature:

- Increasing use of more sophisticated concepts and methodologies for better recognising and analysing the broader organisational networks that emerge or are encountered as governments seek to deliver policy and services: There is better appreciation of different kinds of networks, network dynamics, the reality of multiple goals and interests, the extent to which governments might directly or indirectly shape networks, and how they might work in more productive and collaborative approaches (O'Toole et al. 1997; Klijn and Teisman 1997). Other contributions have shed light on the work of intermediary organisations, not directly in the chain of government hierarchy, 
but supporting policy authorities, line bureaucracies, and delivery agents (for example, Honig 2004a).

- Greater use of principal-agent, public choice, and game-theory perspectives to sharpen insights, testable propositions, and empirical studies on policy implementation: This reflects broader analytic trends in the social sciences, public administration, and political science. It might be thought that such frameworks would tend to focus primarily on the issues having to do with compliance, coordination, and performance (or many of the themes associated with top-down issues), but game theory has also been used to model more dynamic features and behaviour in networked contexts, driven by incentives, rules, the availability of information, monitoring capability, etc. (for example, Klijn and Teisman 1997; Goggin et al. 1990).

- Increased interest in the merits and implications of choosing a mix of policy instruments in order to navigate networks and challenging implementation environments: Scholars have recognised that implementation often involves working with networks, requiring better appreciation of indirect and direct strategies working at the organisational and network levels, in potentially more collaborative environments (de Bruijn and ten Heuvelhof 1997; Howlett 1991, 2005). This in turn requires new forms of leadership, skill and knowledge in government and public administration organisations. Howlett (2005) drew attention to policy and implementation styles, referring to the repertoires and cultures of dominant coalitions, including government agencies and other key interests, in particular policy sectors. Such styles should be understood if they are to be navigated, altered or overcome.

- Increased awareness of whole-of-government, cross-government, horizontal, and multi-level governance environments of implementation: Like the increased awareness of instrument-mix and networked environments, this work suggests broader perspectives on how to approach policy design and implementation strategies, including coordination and mutual adjustment strategies across departments and agencies, and levels of government to better achieve desired outcomes (Management Advisory Committee 2004; Howlett 2005).

- Fostering inter-organisational collaboration: This has long been an important theme in the implementation literature (for example, Van Meter and Van Horn 1975; O'Toole and Montjoy 1984; O'Toole 2003). More recently, it has been explored with respect to the extent of trust and goal congruence as preconditions (Lundin 2007a, 2007b). This work recognises that, in networked contexts, cooperative and adaptive strategies will be required to address tensions arising from competing values and interests (Cline 2000). At a more micro-level, there has been increasing acknowledgement of the importance of getting agencies to work together (Bardach 1997), emerging from early analysis of implementation games (Bardach 1977). Bardach's recent work 
is called 'craftsmanship theory', dedicated to exploring the conditions for bottom-up and lateral collaboration and leadership across agencies, even after top-down announcements.

- Anticipation and collaboration as a strategy for adapting to multi-level, dynamic implementation environments: Complexity and 'wicked problems' are inherent features of many implementation challenges (otherwise it would be relatively straight-forward to proceed with a top-down, programmed strategy), along with ambiguity and value-conflict. Mazmanian and Sabatier (1983) tackled this head on, providing scenarios for leaders to consider when designing strategies (see next section for more detail). Exworthy and Powell (2004) tapped into agenda-setting models to point out that, adopting and implementing policies in the congested state are not only a matter of waiting for the right windows opening across a central government, but also eventually at the local level across delivery agencies, which must collaborate with each other. This presumes that a reasonably good chain of relationships, resources, and incentives extend from the centre of government to regional operations of departments working at the local level.

- Examining how implementing agents get informed, interpret and build skill for the policies they are to implement: Hill (2003) reviews how street-level bureaucrats access 'implementation resources' (ideas, skills, practices, rationale, etc.), contractors, academics, entrepreneurs, foundations, trade journals, and professional associations to interpret policy intentions, ascertain appropriate organisation behaviours, and identify new theories and skills to guide practice. Honig (2004a, 2004b) analyses how intermediary organisations - which she refers to as the 'new middle management' but which stands outside the implementation chain - can serve both policy authorities and implementing agents provide such resources, including policy-specific and system knowledge. Schofield (2004) refers to the challenge of managers interpreting and operationalising policy as 'learned implementation' (see Diagrams 1 (p. 215) and 2 (p. 216)), which can increase motivation and commitment. Spillaine et al. (2002) and Yanow (1993) analyse this as a sense-making and meaning-making activity by individuals, groups, and organisations. Kelman (2005) shows how administrative leaders can identify and unleash 'reform coalitions' from within organisations to implement new policy regimes.

- Closer examination of various organisational capabilities to guide implementation at the centre of government: This writing reviews efforts to build capabilities for oversight such as tracking systems, project management, cabinet implementation units, problem-solving teams, and gateway reviews for major projects (Lindquist 2006; Barber 2007; Marsh and Fawcett 2010). Honig $(2003,2006$ b) considers how central administration offices facilitate 
implementation of educational policy reforms. These can be seen as more modern efforts to shape and fix implementation games (Bardach 1977).

- If implementation can be viewed as part of the democratic governance process, it is legitimate that various interests work hard to reshape policy to meet the needs of groups and communities: Congruent with the adaptation perspective, this possibility was recognised as high-conflict implementation situations by writers such as Matland (1995). DeLeon and deLeon (2002) suggest that a 'consensual theory of implementation' should be developed and, as we discuss below, Patashnik (2008) sees implementation as the next and sustained round of political and policy debate. To some extent, their approach seeks to explicitly recognise and bring politicians back into implementation analysis.

These newer concepts and perspectives have not turned the implementation literature on its head, but sharpen the analysis of many of the themes, issues and strategies it has long broached. As we see later, many have relevance for the kind of advice that would be relevant for public sector agency leaders.

\section{Recent literature on delivering sustainable policy reform}

There has been growing interest in the topic of delivering policy reform that is durable; many of the themes in this literature overlap heavily with the traditional implementation literature, but it is more explicitly political in that it seeks to understand how reforms get anchored and this usually involves political mobilisation and strategies. Barber (2007) and Lindquist (2006) have explored these themes with respect to creating bureaucratic capacities at the centre of government to monitor the progress of government priorities, to fix problems as they arise, and to drive change. Here the focus is more on making good on government priorities.

The writing that has gained most attention and animated a recent ANZSOG conference comes from the work of Erik Patashnik (2003; 2008). While Patashnik relies heavily on the implementation literature, he considers broadly how implementation works at the political level as opposed to the organisational or managerial levels. His work presumes, as does that of deLeon and deLeon (2002) and Matland (1995), that policy implementation often proceeds in contested and conflict-ridden domains, and that concerted political mobilisation is essential for ensuring policy durability and success. It picks up themes found early on in the implementation literature (Bardach 1977) that the implementation phase essentially provides another opportunity to undermine, re-make or elaborate an approved policy. Seen this way, implementation is just another forum for policy contestation. By means of comparing several different cases, Patashnik considers how political and administrative leaders blocked efforts by groups 
opposed to new policy regimes and prevent political erosion of those policies, how they established and mobilised new coalitions of interests in support of the new policy frameworks, and made accommodations to galvanise those interests. An important contribution of this work is that it points to the time horizons required for policy implementation, noting that administrative strategies and tactics cannot likely proceed and succeed without significant political support.

Interestingly, Patashnik'sanalysishasanimportantprecursorintheimplementation literature: Mazmanian and Sabatier (1983) identified implementation scenarios that took into account distinct political and economic contexts, and explicitly acknowledge the time horizons involved when attempting to secure change. It is a more dynamic and strategic way to understand Matland's (1995) analysis (see Diagram 3, next page). In short, Patashnik (2008) provides some case studies to complement these early insights. Crosby (1996) provides similar perspectives on what it takes to anchor structural-adjustment regimes in developing countries, which involves not only mobilising organisational capabilities and political support, but also leadership, new perspectives, skills and time.

There has also emerged work on 'policy execution' in the consulting world (Eggers and O'Leary 2009), invoking terminology from the early days of the literature (Van Meter and Van Horn 1975). This work definitely elicits more attention than policy implementation and is a direct response to the notion that government and public sector organisations often find it difficult to (but must) follow-through on the commitments they have made, and must find contemporary ways to do so. Indeed, the Eggers and the Barber contributions represent a huge strand of for-profit and consulting expertise seeking to bring private-sector techniques and perspectives into the government sector. This work does not contribute much from a conceptual or empirical perspective, and the terminology belies the notion that the challenges are, in fact, quite complex, and require the mobilisation of resources, multiple partners, networks, and learning - themes long in the scholarly and applied literature.

However, Lindquist and Wanna (2011) point to limitations of the 'delivering policy reform' and 'policy execution' perspectives. These perspectives seek to maintain the integrity of original policy designs and consider the ongoing political and administrative effort required to anchor policy over many years in complex institutional environments, the politics for political and administrative leaders of fighting or neutralising interests seeking to undermine the policy reforms, and explore balancing the need to modify reforms so they work better and anchoring the reforms with fidelity to original intentions. Similar to the 'compliance' perspective found in the early implementation literature, the original policy goals are taken as given, and implementation seeks to deliver and execute them, with implication that they are a government priority and require central monitoring and oversight, and thus are infused with a 'performance' orientation. 

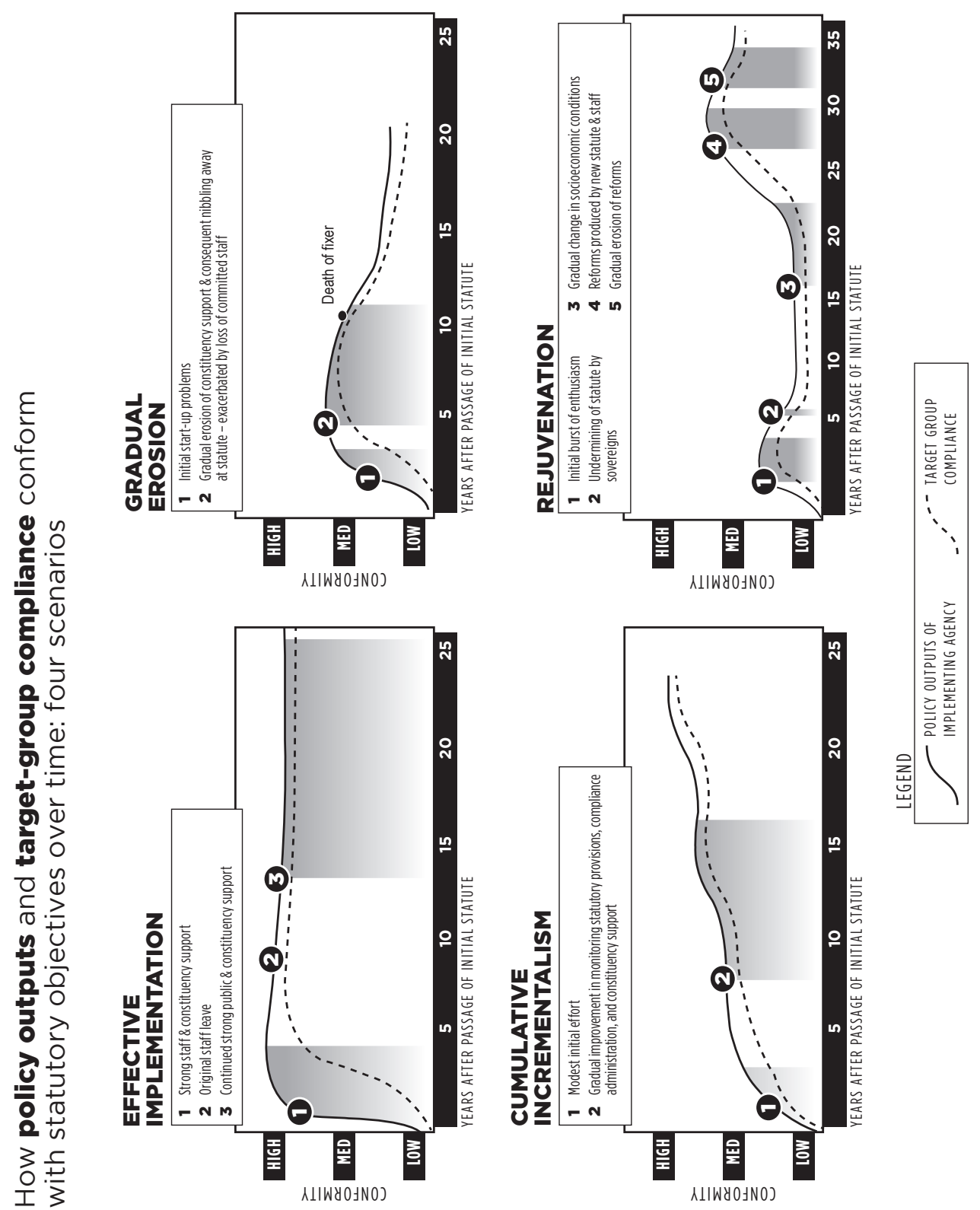

Diagram 3: How policy outputs and target-group compliance conform with statutory objectives over time: Four scenarios

Source: Adapted from Mazmanian and Sabatier 1983. 
These perspectives, however, presume that the logic and theory behind the policy reforms is correct, and that the necessary organisational capabilities are ready, and that the environment remains congruent for its implementation. If these conditions are not met, the policy will have to be adjusted and even reformulated, placing us squarely back into the realm of the adaptive and learning perspectives on implementation. The key tension here concerns the extent to which policy reforms can be modified without losing their integrity and momentum. Indeed, one could envision a tipping point where policies have been anchored, but can be modified in a positive manner without returning to the previous regimes considered to be unproductive or unfair.

\section{Policy implementation: The organisational dimension}

There is a huge literature on organisations and organisational change, most of which focuses on corporate sector and for-profit organisations, where the aim is to increase profitability, meet market and customer needs, etc. Most of this literature, unlike what we have reviewed above, is not focused on public organisations and the complex and fluid environments in which they work (although it does consider the challenge of working in evolving and increasingly networked environments). Conversely, the literature has been heavily informed by organisation theory and change perspectives.

Our purpose here is to identify some key areas to consider how agency leaders of public organisations might anticipate and work towards anchoring policy reforms introduced by governments. We make a distinction between the external-strategic dimension, which is more complicated due to public governance dynamics and constraints, and the internal-strategic dimension, which takes leaders somewhat more squarely into the traditional parameters of the organisational change and development literature. Key themes to consider are as follows:

- Executives must anticipate and prepare organisations for change: This requires scanning and analysing policy and organisational environments, forging new alliances, adopting new technologies, preparing executive colleagues for new responsibilities that might come their way, recruiting at the apex and in critical areas elsewhere in the organisation with these considerations in mind, and communicating with staff and stakeholders (for example, Selznick 1957).

- Executives must assess how organisational culture fits with implementation tasks: Leaders should have a nuanced sense of the nature and source of the culture(s) in their organisation, and which parts may most resist versus be 
capable of taking on new tasks and responsibilities (Wilson 1989). They must ascertain whether new capabilities or units are required for new roles and responsibilities (for example, cope with crisis, adopt new technology, work with clients or partners in a fundamentally different way, deliver higher probity/accountability, etc.).

- Executives must identify new values, meaning, and narratives: The arrival of a new policy often requires that executives understand them as potentially bringing in new values, meanings and priorities, which implies consciously and proactively striking new balances among existing and new values, and developing new language and frames - the process of sense-making — not only for communicating the nature of the new challenges but also linking them to previous understandings and meanings (Barnard 1938; Selznick 1957). Moreover, this needs to be considered not only for the executive's organisation but also the larger network of organisations involved in the implementation.

- New tasks require different expertise and relationships: New policies usually require different or new task structures and ways of doing work, new and different mixes of professional expertise, and imply different task environments in the sense of different organisations to link with inside and outside the organisation (Thompson 1967; Wilson 1989). Agency leaders need to have a fine-grained sense of how specific task environments will shift for implicated units in their organisations, how this will affect more general balances struck across the organisation, and the extent to which this will affect the organisation's sense of mission and culture, whether new understandings and frames need to be developed.

- New tasks could imply structural change and new repertoires: Taking on new tasks goes beyond thinking about new leadership and capabilities in a public organisation. It may also have structural and process implications. As new units are established around new tasks and to instil new values, frames, and culture, structural change may be required in the larger organisation in order to ensure coordination inside and outside the organisation, despite the upheaval and human and other costs of proceeding, and work and decisionmaking may have to proceed in different ways. This needs to be anticipated, monitored, and changed if required.

- Embedding change is hard work: The challenge of anchoring or embedding change with respect to incentives, work practices, cultures, and monitoring is an enduring theme in the organisational change literature (Kotter 1990, 1996), and is no less important for policy implementation. Agency leaders must carefully consider the internal incentives for staff to work in new ways and potentially with different partners. Again, this points to assessing the extent to which there is a need for professional development, new recruitment mixes for leaders and core staff alike, and whether monitoring 
and performance systems are aligned with the new and/or expanded objectives of the organisation.

- Internal change is as important as external change: Typically, agency heads are more focused on external challenges and contingencies, leaving managers and frontline staff to work through implementing strategies. However, the greater the change flowing from policy implementation (breadth and amount of departure from current practice), the more demand there will be for significant organisational change, requiring that leaders have greater strategic engagement with staff and encouraging creative thinking on their part, and, of course, the stakes for dealing with the external environment will be raised considerably. This suggests that leaders need to balance how they allocate their time and strategic effort, since both dimensions are critical for success.

- Leading organisations in networks: Much of the traditional organisational change literature has focused on how leaders can change the values, capabilities and focus of staff. However, in recent years this has been greatly complicated by many organisations having to work in very different ways as a result of new technology, new economic realities, and new expectations of clients and external environments. Increasingly, leaders and their organisations must learn how to work in partnerships, and collaborative and networked arrangements as a matter of course, and sometimes under stress and in fluid environments. This requires finding leaders with the right expertise who are comfortable with working in more collaborative ways.

- Banking on change: Leaders seeking to implement policies and programs must anticipate continual change, arising from not only the evolution of ongoing initiatives but also the arrival of other priorities, such as additional policies to implement, the adoption of new technologies and reporting systems, and the inevitable calls for restraint. The key challenge here is how to maintain engagement, motivation, and strategic focus in the organisation to bed down policy initiatives in the midst of competing priorities and potential turmoil.

There are vast streams of literature on the topics enumerated above, and we cannot do justice to the evolution of thinking in those areas. What is important about the themes and topics identified above is that they bring an organisational dimension to the policy implementation challenges which are the focus of this paper, and which need to be brought to bear on the strategic considerations for agency heads as they prepare themselves and their organisations for moving forward. 


\section{Pulling it all together: Implications for public sector leaders}

This section distils implications from the literature in order to answer the research questions identified in the introduction of this chapter. We have supplemented them with some other questions we think are pertinent to the goals underpinning the literature review.

\section{How is the public sector operating environment unique?}

Both the policy implementation and the policy reform literature study the challenge of converting adopted public policy and government intentions into workable, sustainable programs and achieving intended results. Like the new public management reforms of the late-1980s and 1990s, the policy execution and organisational change literature often seeks to draw lessons from the private sector, but are often simplistic because the public sector environment is more complex and challenging. Figure 1 (opposite) provides a long list of the distinctive features of government responsibilities and associated challenges when attempting to implement new policies.

This list shows that implementing policy in a public sector environment promises to be challenging, and the literature has always understood it as such. We believe that there is little that the public sector can learn from the private sector in this regard. Yes, it would be wonderful to have clear goals, strong and enduring political support, well-aligned stakeholder and service-delivery networks, fully capable lead agencies and partners willing to collaborate, and reasonably stable environments, including funding; but it is difficult to imagine counting on this in a public-sector context. Moreover, new governance challenges have emerged; more fluid political and funding environments, and more attentive media and critics. However, good leaders should be aware of these challenges and, in light of the considerable writing and experience with implementation, presumably be better prepared about how to plan and strategise in the face of them.

\section{How should public sector agency leaders anticipate and prepare for reform?}

This question is interesting because most observers presume that executive leaders of departments and agencies were informed of policy reforms and involved in their design. But these can be heroic assumptions for two reasons: a secretary or chief executive may not have been in the policy design and approval loop, and not privy to all of the considerations and balances that informed the decisions; and a secretary or chief executive may be new to the position or the 
- Governments are typically the custodians (or agents of last resort) of many difficult or wicked problems (homelessness, poverty, crime, health, etc.).

- Policy interventions to these problems often involve working with multiple and often reluctant partners, including different levels of governments and organisations in different sectors. Often these 'partners' actively resisted the adopted policy and/or have other priorities.

- In addition to the general challenge of overload, the attention of political leadership will likely shift due to crisis and other pressing challenges, so securing the government and ministerial engagement for seeing a newly adopted public policy through may be difficult.

- $\quad$ State governments are often recipients of Commonwealth policy initiatives (and may have shaped them through negotiations of some sort) and may have different visions, priorities and preferred approaches to implementing policy.

- $\quad$ State governments and agencies will be the enacting authorities for policies, seeking to deliver policies and programs with one or more department or agency and their regional operations, and often with local governments, non-profit/community groups, and contractors.

- $\quad$ The accountability environment for implementing public sector agencies is unforgiving, with the 24-hour news cycle and the scrutiny of opposition parties and a variety of audit and monitoring agencies, which ensures that delays, oversights, and mistakes can quickly become front-page news and comprise the reputation of governments.

- Despite announced plans of the Commonwealth and state governments, the availability of resources or even political agreements cannot always be counted upon due to factors and considerations beyond the policy to be implemented, suggesting that agency leaders should be prepared for different scenarios and to adapt.

- $\quad$ Beyond the matters of resourcing and political agreements, the structure of incentives and the oversight regime confronting all actors in the delivery chain, including state governments, is critical to ensuring take-up and degree of success.

- $\quad$ The amount of technical and cultural shift inherent in new policy regimes, the lead times for implementation, the number and capabilities of key stakeholders, the nature and quality of reform coalitions, and the readiness and centrality of a lead or supporting agencies vary considerably across policy initiatives creating distinct policy and administrative challenges.

- The extent of political interest of governments in anchoring a reform beyond adoption, the willingness and capabilities of reform opponents to resist, and the skill and adroitness of agency heads in working with political leaders and other stakeholders to further implementation.

\section{Figure 1: Policy and implementation challenges for government}

appointment may have been announced as part of the policy reform or in the wake of it. In either case, the agency head needs to quickly learn of the rationale, expectations, and nuances behind the decision, including the extent to which other levels of government and potential service providers were informed and perhaps had expectations about their roles, resourcing, flexibility, etc.

Public sector leaders, particularly those new to their responsibilities, need to fully understand the origins of the policy, including the needs, pressures, and the politics that led to its enactment. Moreover, they also need to appreciate the range of actors implied in the upstream of policy development and the downstream of implementation, their interests, capabilities, and ability to block 
and further the policy as originally designed. They need to understand the role of their agency in the firmament of actors involved with implementing the policy, as well as its sources of power, influence, and leverage. Much depends, of course, whether an agency was a policy-taker or policymaker in the upstream of the policy development, and whether it will be an implementation lead or contributor in the downstream.

The literature on organisations and change has long suggested that leaders whether of private or public organisations - should be scanning environments for threats and opportunities, and preparing their organisations for change. This implies developing anticipatory repertoires such as strategic planning and environmental scanning, and open-minded and alert leadership. In a public sector context, this would also include regular communication with political leaders and agency-head colleagues, awareness of what comparator sectors and agencies have been experiencing in other jurisdictions, and monitoring stakeholder, client and citizen needs and satisfaction.

\section{Why do reforms become derailed or lose momentum?}

Implementing significant reforms can take several years, and sometimes even decades, for all the foundational elements to put in place, secured, and made sustainable. Two critical questions, however, are: is the reform yet another in a long line of reforms on an overloaded agenda, or if it is a top priority of a government performance-monitoring from the centre?; and, can political attention be sustained at the implementation phase, increasing momentum and the room for manoeuvre for agency leaders as they seek to implement a policy reform? In some cases, reform proposals are driven by politicians (ministers) while in others reforms are often sponsored by agency leaders and or other significant stakeholders (for example, tariff reform).

These questions are important because as has long been apparent from the literature, there is no shortage of factors which could undermine the implementation of a policy. Figure 2 (opposite) provides a long list of the factors working to undermine implementation of policy reforms. Despite this depressingly long list of negative dynamics and possibilities, many policies and substantial programs and reforms do get enacted, flowing from good leadership and no small amount of foresight, creativity, and good fortune (Patashnik 2008; Lindquist, Vincent and Wanna 2011). We turn to these factors next.

\section{How do public sector agency leaders make reform stick?}

If a policy is well-designed and properly resourced, and the environment congruent with expectations inherent in the design, then it is possible for a programmed solution to be implemented and made to stick - otherwise there 
- Unclear or inconsistent policy designs, including poor choice of instruments.

- Under-specification of a new policy variously in order to secure approval, because not enough was known about how things work, or it was understood there will be 'learning-by-doing'.

- Insufficient recognition of the inherent complexity not only of the problem seeking to be remedied but also of the solution arrived at as a 'public policy' (i.e. making the policy work is more complex than imagined at the design phase).

- Value conflicts and interest conflicts, impossibility of securing consensus, agreement on means and ends, and how to evaluate outcomes.

- Insufficient anticipation of implementation challenges, including the motivations and power of intermediary organisations and street-level bureaucrats, and the incentives and resources required to engage, mobilise and influence them as well as the policy's target groups.

- Insufficient political and administrative leadership assigned for implementing the policy reform. Unrealistic expectations built into the theory informing the policy, the outcomes that could be reasonably achieved with the instruments and resources at hand, and - to the extent that the policy adoption involved 'emulation' - the extent to which similar cultural conditions exist.

- $\quad$ Shrewd political and other interests actively seeking to undermine adopted policies. Insufficient mobilisation of reform champions among beneficiaries as well as insufficient awareness or strategies for dealing with interests benefitting from the previous policy regime.

- Whether intentionally or not, public and other organisations in the implementation chain which either inadvertently or systematically bend (and sometimes re-formulate) the adopted policy into repertoires consistent with prior programs, organisational capabilities, and values.

- Agency leaders have insufficient repertoires for collaboration and for anchoring change (new work patterns, incentives, value balances, frames, etc.).

- Inability to identify new external partners and/or work in new ways in order to achieve the objectives inherent in the policy reforms.

- Insufficient monitoring or delayed feedback on the activities of agents in the delivery and oversight chain to inform timely adjustment and learning.

- Growing awareness that a reform may be unworkable, along with insufficient ability or interest to make needed adjustments in the policy framework and/or implementation arrangements.

- Growing attention of the media and political opponents about implementation gaps, whether the policy was proceeding as originally planned or in a more emergent manner.

- Insufficient recruitment and evolution in relevant professional repertoires, skills and perceptions over time, and insufficient awareness of the rationale and requirements of the new policy.

- Insufficient repertoires for monitoring and assessing progress, sharing that information with partners, political leaders, and others in favour of the new policy regime.

- Lead implementing agencies are given other government priorities or crises to manage, government interest in securing reform dissipates, and turnover in top executive leadership.

- The sponsoring environment continually shifts (including new government priorities, budget and other constraints), complemented by insufficiently anticipatory, adaptive, and creative leadership, which, in turn, leads to strategic and operational overload.

Figure 2: Factors working to undermine implementation of policy reforms 
will be many adjustments along the way. Even Patashnik's (2003) 'policy reform' stream of thinking sees that successful implementation requires ongoing political attention, administrative adaptation, and likely modest re-shaping of the original policy. It has to be acknowledged that sometimes policies as enacted, for a variety of reasons, need to be significantly changed or even dropped. Rather than enumerate a list opposite the points identified in Figure 2, we instead make some broad points.

First, the literature indicates that policy gets shaped and reshaped at all phases of the policy cycle. Accordingly, implementation can be seen not just as a matter of finding strategies to enact a policy, but also an opportunity to refine or improve what otherwise could have been a broad or imperfect policy through more detailed planning, design, and learning from different approaches to implementation across a system or region. Implementation can be seen as an opportunity for policy adjustment or policy elaboration, even if others see this as program design and implementation. It requires recognising the extent of ambiguity in the policy as announced (and what needs to be further specified, negotiated or learned about), the extent of political conflict, and what operational skills and cultures must shift inside and outside pertinent public agencies.

In short, it is only in certain circumstances that agency leadership can simply be about securing approvals and authorities. It is far more likely that implementation leadership will be about operationalising, elaborating and specifying broader policy goals, securing necessary resources for implementation, assembling the right capabilities and educating implementers down the line and in the field, as well as collaborating, negotiating, and forming the productive administrative coalitions with other agencies, levels of government, and non-government partners, including non-profit, community and for-profit entities. Indeed, the great tension emerging from the literature is the need for leaders to be goal-oriented but contingent, knowing when to drive forward and execute, and when to compromise, adapt, and perhaps achieve goals in ways different than originally imagined. With these broader considerations in mind, Figure 3 (opposite) identifies more specific lessons for keeping reforms on track and anchored.

A crucial insight from the literature is that policy implementation is not simply a strategic management and administration activity, it also involves political management - good leaders shrewdly engage stakeholders, build and support coalitions in support of reforms, and engage political masters at the right time. It is about continuously maintaining, galvanising and mobilising support for reforms inside and outside agencies. 
- Negotiate and work with political leaders to elicit ongoing support for implementing initiatives.

- $\quad$ Keep ministers informed of progress and identify how they might make strategic contributions as required, even if not a top government or ministerial priority.

- Map the full range of implicated interests, networks and coalitions at play.

- $\quad$ Find ways to strengthen entities that will benefit from and support reform implementation.

- $\quad$ Forge strong working relationships with agencies across levels of government to build and strengthen a reform coalition, and institute regular opportunities for reporting and strategising.

- Develop realistic time frames for anchoring reforms (two years or a decade) to manage internal and external expectations, and focus energies on foundational elements of reforms.

- Understand current incentives/disincentives and develop a new incentive structure appropriate to the implemented policy.

- $\quad$ Steadily recruit the right leaders and technical expertise in the agency and the broader implementing network.

- Ensure sufficient implementation resources to support administrative and delivery staff.

- If required, institute sufficient structural change at appropriate junctures, but otherwise rely on good communications, temporary task force and coordination structures.

- $\quad$ Develop a strategic approach to communications: ensure two-way channels with staff, external coalitions, delivery partners, and sponsors in government; encourage feedback and monitoring; and institute repertoires for informing the broader public about progress.

- $\quad$ Develop robust, focused and relevant reporting systems that recognise the emergent and evolutionary quality of most implementation initiatives.

- Institute staff engagement and client satisfaction feedback capabilities and repertoires, and ensure timely collection of data.

- Design reporting systems to inform future evaluations and assessments of the performance of implemented policies, whether planned or emergent.

Figure 3: Keeping policy implementation on track: Repertoires for agency leaders

\section{How do public sector agency leaders know when implementation has succeeded?}

Implementation is often a moveable feast, with plans and objectives evolving in response to political and other external circumstances, as well as from learning and change. Furthermore, gauging whether a policy reform has achieved intended outcomes and new thresholds of performance is different from assessing whether a reform-as-enacted stuck, for better or worse. With these caveats, several indicators inferred from the literature are displayed in Figure 4. 
- Information and feedback is regularly obtained from key stakeholders and beneficiaries of the new policy, and the emerging regime reflects stakeholder input on making it more workable.

- $\quad$ Ability to demonstrate progress even if the causal link between the policy as implemented and the outcomes are unclear or contested, as well as respect for meeting project management targets, understanding the limits of policy approach, and what accounts for differences.

- $\quad$ Trust and shared expectations were built with collaborating departments, agencies, delivery agents, and intermediary organisations.

- $\quad$ Expectations about what could be accomplished with the implemented policy and available resources were met, even if issues have been identified, and political leaders and the public are aware what the reforms have achieved.

- Key stakeholders who opposed the reforms see key objectives and some of their concerns are met, and that other stakeholders, agencies, and delivery agents have coalesced around the reform.

- The right agency leaders and managers were put in place to institutionalise the reforms as programs, and the next generation of leaders selected and recruited based on the new model.

- $\quad$ Changes are embedded into repertoires; new recruits know little about what was previously done - it is no longer relevant or a festering matter.

- The reforms are not only insulated from legislative unpacking and relatively immune to end-runs through other policies and regulatory decisions.

- $\quad$ Success is recognised internally and sought-after by other jurisdictions.

- $\quad$ The leaders who guided change among the agencies in the implementation network move on to take up new challenges and opportunities.

- New thresholds of performance are met (for example, speed, consistency, tailoring, fewer backlogs), but ministers, executives and stakeholders take up issues within the new policy framework.

\section{Figure 4: How might agency leaders know policy implementation has succeeded?}

That said, aside from a 'performance' perspective (timelines met and outcomes achieved, usually under a programmed implementation scenario), the literature does not have definitive views on what might constitute success when implementation becomes increasingly emergent, negotiated, and adaptive. Moreover, these notions of success may vary across initiatives and the extent to which there are real gaps in anticipated and touted performance with respect to costs, outputs and outcomes.

\section{Other lessons from the policy implementation and reform literature}

There is no need to repeat the many lessons from the implementation literature for agency heads to consider. Successful executive leadership during any kind of policy implementation will be about differing degrees of responsibility for 
achieving success, balancing competing demands in an evolving environment, and preparing a dynamic reality and different scenarios. With this in mind, we want to step back and consider two significant lessons.

First, when attempting to understand implementation (and develop a strategic posture), much depends on one's vantage point. The literature does a good, if not bewildering job considering the different actors involved in implementation: politician, executive, middle manager, frontline delivery staff, recipients (citizens, communities, etc.), or observer (scholar, evaluator, etc.). Not only are these equally legitimate and material perspectives, those designing and implementing policy should seriously consider the other levels of analysis in order to better design policy, anticipate how to coordinate implementation, and work with inevitable frontline dynamics of other actors.

A second implication is that, when making assessments and drawing lessons for designing better policy and for strategic leadership, much depends on the specific policy domain (transportation systems, energy, disability, water distribution, etc.) and the governance context (country, state, local/community, network). This greatly affects the distribution of power, how decisions get made, where capabilities are distributed, and the specific roles for different public organisations as well as the strategic challenges confronting agency heads. An important implication is that agency leaders would do well to put themselves in the strategic shoes of other leaders, when making assessments and attempting to develop strategic decisions to guide implementation.

\section{Conclusion: An integrative, strategic framework for leaders}

There is no shortage of frameworks in the policy implementation literature, but most were developed for analytic purposes rather than for informing strategic leadership. That said, the implications of the literature for strategic leadership are numerous. Indeed, it identifies so many variables, factors, and perspectives on implementation that it would be easy to develop a lengthy checklist of all the things that should be aligned and done in order for a policy implementation to be successful (see, for example, the checklists in Bridgman and Davis 2000, chapters 10 and 13).

We caution against relying on the checklist approach. Such checklists do not anticipate the different kinds of policies that need to be implemented, the different contexts in which policies get implemented, nor the extent to which evolving environments can directly and indirectly pose new and anticipated challenges. Though the literature does an excellent job in identifying the great 
range of actors which might be implicated in an implementation (ministers, executives, middle managers, frontline bureaucrats, intermediary organisations, counterparts in other governments, contractors, community groups, interest groups, etc.), there is little focus on the challenges of specific public organisational leaders (other than those actually driving the change) and their executive teams, how they might support ministers and governments, nor how strategic priorities might vary across these agency leadership teams depending on the role they play in particular implementation firmaments.

Rather than develop another checklist, it is better to develop a framework that is more strategic and assists agency heads to survey contexts, identify emerging policy and implementation initiatives, and assess the preparedness of their agencies and networks to further impending change. It must acknowledge the extent to which circumstances and challenges can vary across enacted policies. Much of what makes for good policy implementation and organisational change is well-known, but varies considerably in lesson-drawing for public sector leaders with respect to:

- specific situational contexts - crisis-driven, central government priority driving a mandate, a central invention or policy developed closely with implementing agencies, etc.;

- scale of policy interventions - broader interventions imply more agencies, external partners, and possibly levels of government, etc. — which implies different roles for different agencies and different combinations of partners and other organisations to contend with;

- fluidity of political and policy environment - new and changing priorities, crises — which requires thinking in scenario-based and multiple-level (political and administrative) terms;

- centrality of an executive's organisation to implementing and realising the interventions - acting as a partner to many other organisations during implementation is very different from acting as a lead implementation agency;

- extent of alignment of an agency's core capabilities for the implementation tasks at hand, and the extent to which new capabilities, repertoires, and relationships have to be built in order to implement and embed a new policy and delivery regime;

- extent of policy coherence and an implementation plan understood by different stakeholders, which is different from a policy that is flawed in terms of logic or not well thought out, or deliberately underspecified, and which requires more flexibility, learning, and emergence in implementation;

- extent to which implementation partners know and have worked with each other, the amount of trust, and the extent to which implementation resources independent of specific agencies might be available to tap into; and 
- extent to which the time frames envisioned for successfully implementing and anchoring new policies are understood - three months, two years, a decade?

These variables, when combined, produce considerably different strategic fields in which executives might attempt to move forward with an implementation checklist.

A strategic implementation framework should focus on key strategic moments for agency heads, encouraging them and their executive teams to ask the right questions. Although Berman $(1980,1978)$ suggested three phases mobilisation, implementation, and institutionalisation - given that agency heads need to learn about the genesis of new policies, and that they will need adjustment reconsideration at some point, the following five phases might be worth considering: (1) understanding a policy's genesis; (2) planning and mobilising for implementation; (3) implementation as strategy and management; (4) institutionalisation (embedding); and (5) appraising policy regimes. What would make a framework organised around these phases interesting and productive is that the strategic context for every implementation is unique and usually evolving. Such a framework should contain questions probing the understanding of agency heads about whether the policy as originally conceived is working, whether new capabilities and relationships need to be developed, whether new strategies and tactics are required in light of evolving environments or learning about the real incentives and behaviours of delivery agents and target groups, and what strategies are required to deal with interests seeking to undermine the new policy regime.

All of this should be generally distilled into a visual organising framework that identifies all of the key variables and considerations broached in the literature review, organised around the phases identified above. Distinct questions and pointers could be dealt with under each phase, as well as how particular themes (for example, handling the politics of interests, changing environments, motivating staff and agents, working with partners, monitoring and performance, etc.) might evolve across the phases. Each phase would contain its own scoping SWOT-type questions (strengths, weaknesses, opportunities and threats) and call on executives to adopt a different strategic focus in the service of the broader implementation. 
New Accountabilities, New Challenges

\section{References}

Barber, M. 2007, Instruction to Deliver: Tony Blair, public services and the challenge of achieving targets, Politicos, London.

Bardach, E. 1977, The Implementation Game: What happens after a bill becomes law, MIT Press, Cambridge.

Bardach, E. 1997, Getting Agencies to Work Together: The practice and theory of managerial craftsmanship, Brookings Institution, Washington, DC.

Barnard, C. 1938, The Functions of the Executive, Harvard University Press, Boston.

Barrett, S. M. 2004, 'Implementation Studies: Time for a revival?: Personal reflections on 20 years of implementation studies', Public Administration 82(2), pp. 249-262.

Barrett, S. and C. Fudge (eds) 1981, Policy and Action, Methuen, London.

Berman, P. 1978, 'Macro- and Micro-Implementation', Public Policy 26, pp. 165179.

Berman, P. 1980, 'Thinking about Programmed and Adaptive Implementation: Matching strategies to situations', in H. Ingram and D. Mann (eds), Why Policies Succeed or Fail, Sage, Beverly Hills, pp. 205-227.

Bridgman, P. and G. Davis 2000, 'Implementation' and 'Checklists for Policy Development', in The Australian Policy Handbook, 2nd ed., Allen \& Unwin, Crows Nest.

Cline, K. D. 2000, 'Defining the Implementation Problem: Organizational management versus cooperation', Journal of Public Administration Research and Theory 10(3), pp. 551-571.

Crosby, B. L. 1996, 'Policy implementation: The organizational challenge', World Development 24(9), pp. 1403-1415.

de Bruijn, J. A. and E. F. ten Heuvelhof 1997, 'Instruments for Network Management', in W. J. M. Kickert, E.-H. Klijn, and J. F. M. Koppenjan (eds), Managing Complex Networks: Strategies for the public sector, Sage, London, pp. 119-136.

deLeon, P. 1999a, 'Cold Comfort Indeed', Policy Currents 8(4), pp. 5-8.

deLeon, P. 1999b, 'The Missing Link Revisited: Contemporary implementation research', Policy Studies Review 16, pp. 311-338. 
deLeon, P. and L. deLeon 2002, 'What Ever Happened to Policy Implementation', Journal of Public Administration Research and Theory 12(4), pp. 467-492.

Eggers, W. D. and J. O'Leary 2009, If We Can Put a Man on the Moon .... Getting big things done in government, Harvard Business School Press, Boston.

Elmore, R. F. 1979, 'Backward Mapping: Implementation research and policy decisions', Political Science Quarterly 94(4), pp. 601-616.

Exworthy, M. and M. Powell 2004, 'Big Windows and Little Windows: Implementation in the "congested state"', Public Administration 82(2), pp. 263-281.

Goggin, M. L., A. Bowman, J. Lester, and L. O'Toole 1990, Implementation Theory and Practice: Toward a third generation, Scott Foresman, Little, Brown, Glenview.

Hill, H. C. 2003, 'Understanding Implementation: Street-level bureaucrats' resources for reform', Journal of Public Administration Research and Theory 13(3), pp. 265-282.

Hill, M. 1997, 'Implementation Theory: Yesterday's issue?' Policy and Politics 25(4), pp. 375-385.

Hill, M. and P. Hupe 2009, Implementing Public Policy: An introduction to the study of operational governance, 2nd ed., Sage, London.

Hjern, B. 1982, 'Implementation Research: The link gone missing', Journal of Public Policy 2(3), pp. 301-308.

Hogwood, B. W. and L. Gunn 1984, Policy Analysis for the Real World, Oxford University Press, Oxford.

Honig, M. I. 2003, 'Building Policy from Practice: Central office administrators' roles and capacity in collaborative educational policy implementation', Educational Administration Quarterly 39(3), pp. 292-338.

Honig, M. I. 2004a, 'The New Middle Management: Intermediary organizations in education policy implementation', Educational Evaluation and Policy Analysis 26(1), pp. 65-87.

Honig, M. I. 2004b, 'Where's The "Up" in Bottom-Up Reform?', Educational Policy 18(4), pp. 527-561. 
Honig, M. I. 2006a, 'Complexity and Policy Implementation: Challenges and opportunities for the field' in M. I. Honig (ed.), New Directions in Education Policy Implementation: Confronting complexity, State University of New York Press, Albany, pp. 1-23.

Honig, M. I. 2006b, 'Street-Level Bureaucracy Revisited: Frontline district central-office administrators as boundary spanners in educational policy implementation', Educational Evaluation and Policy Analysis (28)4, pp. 357383.

Howlett, M. 1991, 'Policy Instruments, Policy Styles, and Policy Implementation: National approaches to theories of instrument choice', Policy Studies Journal 19(2), pp. 1-21.

Howlett, M. 2005, 'What is a Policy Instrument?: Tools, mixes, and implementation styles', in P. Eliadas, M. Hill and M. Howlett (eds), Designing Government: From instruments to governance, McGill-Queen's University Press, Montreal and Kingston, pp. 31-50.

Ingraham, P. W. and L. E. Lynn, Jr. (eds) 2004, The Art of Governance: Analyzing management and administration, Georgetown University Press, Washington, DC.

Ingram, H. 1977, 'Policy Implementation Through Bargaining: The case of federal grants-in-aid', Public Policy 25, pp. 499-526.

Ingram, H. and D. Mann (eds) 1980, Why Policies Succeed or Fail, Sage, New York.

Kelman, S. 2005, Unleashing Change: A study of organizational renewal in government, Brookings Institution, Washington, DC.

Kettunen, P. 2000, 'Implementation Approach: The political scientist's perspective', Policy Currents 10:1-2, pp. 3-5.

Klijn, E. H. and G. R. Teisman 1997, 'Strategies and Games in Networks', in W. J. M. Kickert, E.-H. Klijn, and J. F. M. Koppenjan (eds), Managing Complex Networks: Strategies for the public sector, Sage, London, pp. 98-118.

Kotter, J. P. 1990, 'What Leaders Really Do', Harvard Business Review, pp. 103111.

Kotter, J. P. 1996, Leading Change, Harvard Business Press, Boston.

Lester, J. P., A. M. O'Bowman, M. G. Goggin, and L. J. O'Toole, Jr. 1987, 'Public Policy Implementation: Evolution of the field and agenda for future research', Policy Studies Review 7(1), pp. 200-216. 
Lester, J. P., and M. L. Goggin 1998, 'Back to the Future: The rediscovery of implementation studies', Policy Currents 8, pp. 1-9.

Lester, J. P. 2000, 'Back to the Future in Implementation Research: A response', Policy Currents 10(1-2), pp. 2-5.

Lindquist, E. A. 2006, 'Organizing for Policy Implementation: The emergence and role of implementation units in policy design and oversight', Journal of Comparative Policy Analysis 8(4), pp. 311-324.

Lindquist, E. A. and J. Wanna 2011, 'Delivering Policy Reform: Making it happen, making it stick', in E. A. Lindquist, S. Vincent and J. Wanna (eds), Delivering Policy Reform: Anchoring significant reforms in turbulent times, ANU E Press, Canberra.

Lindquist, E. A., S. Vincent and J. Wanna (eds) 2011, Delivering Policy Reform: Anchoring significant reforms in turbulent times, ANU E Press, Canberra.

Lipsky, M. 1980, Street-Level Bureaucrats: The dilemmas of individuals in public services, Russell Sage Foundation, New York.

Lundin, M. 2007a, 'When Does Cooperation Improve Policy Implementation?', Policy Studies Journal 35(4), pp. 629-652.

Lundin, M. 2007b, 'Explaining Cooperation: How resource interdependence, goal congruence, and trust affect joint actions in policy implementation', Journal of Public Administration Research and Theory 17(4), pp. 651-672.

Lynn, Jr., L. E., C. J. Heinrich and C. J. Hill 2001, Improving Governance: A new logic for empirical research, Georgetown University Press, Washington, DC.

Management Advisory Committee 2004, 'Connecting Government: Whole of government responses to Australia's priority challenges', Australian Public Service Commission, Canberra.

Marsh, D. and P. Fawcett 2012, 'Policy Transfer and Policy Success: The case of the gateway review process', Government and Opposition 47(2), pp. 162-185.

Matland, R. E. 1995, 'Synthesizing the Implementation Literature: The ambiguity-conflict model of policy implementation', Journal of Public Administration Research and Theory 5(2), pp. 145-174.

May, P. J. 2003, 'Policy Design and Implementation', in B. Guy Peters and J. Pierre (eds), Handbook of Public Administration, Sage, London, pp. 223-233.

Mazmanian, D. A. and P. A. Sabatier (eds) 1981, Effective Policy Implementation, Heath, Lexington. 
Mazmanian, D. A. and P. A. Sabatier 1983, Implementation and Public Policy, Scott, Forseman, Glenview.

Meier, K. 1999, 'Are We Sure That Lasswell Did it This Way?: Lester Goggin and implementation research', Policy Currents 9(1), pp. 5-8.

Meyers, M. K., and S. Vorsanger 2003, 'Street-Level Bureaucrats and the Implementation of Public Policy', in B. Guy Peters and J. Pierre (eds), Handbook of Public Administration, Sage, London, pp. 245-255.

Montjoy, R. S. and L. O'Toole Jr. 1979, ‘Toward a Theory of Policy Implementation: An organizational perspective', Public Administration Review 39(5), pp. 465476.

Nakamura, R. T. and F. Smallwood 1980, The Politics of Policy Implementation, St. Martin's, New York.

O'Toole, Jr., L. J. 2000, 'Research on Policy Implementation: Assessment and Prospect', Journal of Public Administration Research and Theory 10(2), pp. 263-288.

O'Toole, Jr., L. J. 2003, 'Interorganizational Relations in Implementation', in B. Guy Peters and J. Pierre (eds), Handbook of Public Administration, Sage, London, pp. 234-244.

O'Toole, Jr., L. J. 2004, 'The Theory-Practice Issue in Policy Implementation Research', Public Administration 82(2), pp. 309-329.

O'Toole, Jr., L. J., K. I. Hanf and P. L. Hupe 1997, 'Managing Implementation Processes in Networks', in W. J. M. Kickert, E.-H. Klijn, and J. F. M. Koppenjan (eds), Managing Complex Networks: Strategies for the public sector, Sage, London, pp. 137-151.

O'Toole, Jr., L. J. and R. S. Montjoy 1984, 'Interorganizational Policy Implementation: A theoretical perspective', Public Administration Review 44(6), pp. 491-503.

Pal, L. A. 1997, Beyond Policy Analysis: Public issue management in turbulent times, Nelson, Scarborough.

Palumbo, D. J., and D. J. Calista (eds) 1990, Implementation and the Policy Process: Opening up the black box, Greenwood, New York.

Patashnik, E. M. 2003, 'After the Public Interest Prevails: The political sustainability of policy reform', Governance 16(2), pp. 203-234. 
Patashnik, E. M. 2008, Reforms at Risk: What happens after major policy changes are enacted, Princeton University Press, Princeton.

Potoski, M. 2001, 'Implementation, Uncertainty and the Policy Sciences', Policy Currents 11(1-2), pp. 2-5, 283-308.

Pressman, J. L., and A. Wildavsky 1973, Implementation: How great expectations in Washington are dashed in Oakland, or why it's amazing that federal programs work at all, University of California Press, Berkeley.

Rittel, H. W. J. and M. M. Webber 1973, 'Dilemmas in a General Theory of Planning', Policy Sciences 4, pp. 155-169.

Sabatier, P. A. 1986, 'Top-Down and Bottom-Up Approaches to Implementation Research: A critical analysis and suggested synthesis', Journal of Public Policy 6(1), pp. 21-48.

Saetren, H. 2005, 'Facts and Myths about Research on Public Policy Implementation: Out-of-fashion, allegedly dead, but still very much alive and relevant', Policy Studies Journal 33(4), pp. 559-582.

Schofield, J. 2001, 'Time for a Revival? Public Policy Implementation: A review of the literature and agenda for future research', International Journal of Management Review 3(3), pp. 245-263.

Schofield, J. 2004, 'A Model of Learned Implementation', Public Administration 82(2), pp. 283-308.

Schofield, J. and C. Sausman 2004, 'Symposium on Implementing Public Policy: Learning from theory and practice: Introduction', Public Administration 82(2), pp. 235-248.

Schneider, A. 1999, 'Terminator? What, Me?: Some thoughts about the study of policy implementation', Policy Currents 9(1), pp. 1-5.

Selznick, P. 1957, Leadership in Administration: A sociological perspective, University of California Press, Berkeley.

Spillaine, J. P., B. J. Reiser and T. Reimer 2002, 'Policy Implementation and Cognition: Reframing and refocusing implementation research', Review of Educational Research 72(3), pp. 387-431.

State Services Authority 2011, 'Making Public Policy Stick: Policy implementation literature report', State Government of Victoria State Services Authority, Melbourne. Available at: http://www.ssa.vic.gov.au/images/stories/product_ files/862_making\%20public\%20policy\%20stick.PDF. 
Stoker, R. P. 1989, 'A Regime Framework for Implementation Analysis: Cooperation and reconciliation of federalist imperatives', Policy Studies Review 9(1), pp. 29-49.

Thompson, J. D. 1967, Organizations in Action, McGraw-Hill, New York.

Van Horn, C. E. 1979, Policy Implementation in the Federal System, Heath, Lexington.

Van Meter, D. S. and C. E. Van Horn 1975, 'The Policy Implementation Process: A conceptual framework', Administration and Society 6(4), pp. 445-488.

Weatherly, R. and M. Lipsky 1977, 'Street-Level Bureaucrats and Institutional Innovation: Implementing special education reform', Harvard Educational Review 47(2), pp. 171-197.

Williams, W. et al. 1982, Studying Implementation: Methodological and administrative issues, Chatham House, Chatham.

Williams, W. 1980, The Implementation Perspective: A guide for managing social service delivery programs, University of California Press, Berkeley.

Wilson, J. Q. 1989, Bureaucracy, Basic Books, New York.

Winter, S. C. 1999, 'New Directions for Implementation Research', Policy Currents 8(4), pp. 1-5.

Winter, S. C. 2003, 'Implementation Perspectives: Status and reconsideration', in B. G. Peters and J. Pierre (eds), Handbook of Public Administration, Sage, London, pp. 212-222.

Yanow, D. 1993, 'The Communication of Policy Meanings: Implementation as Interpretation and Text', Policy Sciences 26(1), pp. 41-61. 
This text taken from New Accountabilities, New Challenges, edited by John Wanna, Evert A. Lindquist and Penelope Marshall, published 2015 by ANU Press, The Australian National University, Canberra, Australia. 